\title{
ABRINDO ESPAÇO PARA A CHINA NA ECONOMIA MUNDIAL*
}

\author{
DANI RODRIK \\ TRADUÇÃO DE FERNANDO RUGITSKY
}

\section{RESUMO}

$\mathrm{O}$ artigo sugere que o crescimento da China (e dos demais países em desenvolvimento que se prenderam a superávits comerciais ou exportações como seus "motores do crescimento") depende da produção de bens comercializáveis. Nem as exportações nem os superávits comerciais são cruciais, uma vez que a demanda doméstica por bens comercializáveis possa ser ampliada paralelamente à oferta doméstica.

PALAVRAS-CHAVE: China; crescimento econômico; subvalorização cambial; politica industrial.

\section{ABSTRACT}

The article suggests that economic growth of China (and other developing nations that have gotten hooked on trade surpluses or exports as their "engines of growth") depends on the output of tradables. Neither exports nor trade surpluses are key as long as domestic demand for tradables can be increased alongside the domestic supply.

KEYWORDS: China; economic growth; currency undervaluation; industrial policy.

[*] Publicado originalmente em American Economic Review: Papers $\mathcal{E}$ Proceedings, vol. 100, $\mathrm{n}^{\circ} 2$, maio de 2010, pp. 89-93.

[1] Partes deste artigo baseiam-se amplamente no artigo de Rodrik, Dani. "Growth after the Crisis" <www.hks.harvard.edu/fs/drodrik/ Research\%2opapers/Growth\%20 after\%2othe\%2ocrisis.pdf $>$, acessado em 03/o1/2010. Agradeço a Nicholas Lardy, Yingyi Qian, Anthony Saich, Shang-Jin Wei, Wing Thye Woo e Martin Whyte por discussões muito proveitosas sobre a China.
Ao sair da crise, a economia mundial enfrenta duas exigências aparentemente contraditórias ${ }^{1}$. Por um lado, para garantir a estabilidade macroeconômica global e impedir uma reação protecionista, é necessário evitar os grandes desequilíbrios de conta-corrente que a economia mundial enfrentou na escalada da crise. Por outro, a retomada do rápido crescimento nas nações em desenvolvimento exigirá a retomada da participação no mercado global de bens comercializáveis que esses países haviam conquistado.

O desafio de conciliar essas duas exigências é perfeitamente exemplificado pela conflituosa relação bilateral entre os Estados Unidos e a China. Os formuladores de política norte-americanos 
(e europeus) culpam a China pela subvalorização do renminbi, que é, segundo eles, a causa principal do imenso superávit comercial chinês. Os líderes chineses resistem à pressão, temendo que a apreciação cambial mine a competitividade dos produtos chineses nos mercados internacionais, afete as exportações e prejudique o crescimento. A posição do Ocidente em relação a essa preocupação é a de que a China precisa substituir a demanda externa por demanda doméstica como motor do crescimento.

Mas, se o crescimento depende principalmente da oferta de produtos industrializados modernos e outros comercializáveis e não da oferta de serviços e produtos não comercializáveis, conforme argumentarei aqui, a posição chinesa tem mais força do que seus críticos querem admitir. A solução convencional para o superávit de conta-corrente da China, uma combinação de expansão de gastos e apreciação cambial, deslocaria a estrutura da economia chinesa dos produtos comercializáveis para os não comercializáveis. Isso poderia ser bom para o equilíbrio macroeconômico da China e demais países, mas muito provavelmente teria efeitos adversos sobre o crescimento chinês - talvez suficientemente amplos para pôr em perigo a estabilidade social e política do país.

A boa notícia é que não há conflito inerente entre o crescimento da China e o desejo dos demais países de ter contas externas razoavelmente equilibradas. O que importa para o crescimento de nações em desenvolvimento como a China não é o tamanho do seu superávit comercial nem o volume das suas exportações, mas a sua produção de bens comercializáveis não tradicionais, que pode expandir sem limites desde que a demanda doméstica (por esses mesmos bens) cresça simultaneamente.

Existe, então, uma solução simples.Pode-se apreciaro renminbi,eliminando assim o superávit comercial chinês, desde que sejam implementadas políticas complementares para sustentar mais diretamente os produtos comercializáveis modernos. Tais políticas, combinadas com políticas macroeconômicas que visem ao ajuste da conta-corrente, podem alcançar tanto o equilíbrio externo quanto uma mudança estrutural que beneficie os produtos comercializáveis modernos. É melhor subsidiar produtos comercializáveis diretamente do que subsidiá-los indiretamente por meio da taxa de câmbio, o que significa taxar também o consumo doméstico desses produtos.

Há muitas maneiras de aumentar a lucratividade dos produtos comercializáveis, incluindo a redução do custo de insumos não comercializados e serviços por meio de investimentos em infraestrutura adequadamente direcionados. Mas medidas de política industrial, incluindo subsídios explícitos aos produtos comercializáveis, também podem fazer parte do arsenal ${ }^{2}$. Assim, uma implicação importanteé
[2] Rodrik. "Normalizing Industrial Policy". Commission on Growth and Development Working Paper, $\mathrm{n}^{\circ} 3$, 2008; Rodrik. "Growth after the Crisis", op. cit. 
[3] Rodrik. "The Real Exchange Rate and Economic Growth". Brookings Papers on Economic Activity, $\mathrm{n}^{\circ}$, 2008, pp.365-412. que o ambiente internacional terá que ser mais tolerante a tais políticas, neutralizando os efeitos na balança comercial por meio de ajustes adequados na taxa de câmbio real. Permissividade em relação à política industrial é o "preço" a ser pago por uma maior disciplina sobre as práticas cambiais e os desequilíbrios externos.

\section{SE DESEJA CRESCER, PROMOVA PRODUTOS COMERCIALIZÁVEIS}

O queé comum às experiências do Japão, da Coreia do Sul, da China e de todas as demais estrelas do crescimento é que elas basearam suas estratégias no desenvolvimento de capacidades industriais, em vez de se especializarem de acordo com suas principais vantagens comparativas. Todas elas tornaram-se superpotências industriais em curto prazo - muito mais curto do que se poderia esperar considerando os recursos de que dispunham. Acesta de exportações da China foi criada por meio de investimentos públicos estratégicos e políticas industriais que forçaram as companhias estrangeiras a transferir tecnologia; consequentemente, assemelha-se à de um país três ou quatro vezes mais rico.

Eis a lição: países com crescimento acelerado são aqueles capazes de empreender uma transformação estrutural rápida de atividades de baixa produtividade ("tradicionais") para atividades de alta produtividade ("modernas"). Tais atividades modernas consistem, na maior parte, na produção de produtos comercializáveis e, dentre os comercializáveis, de produtos industriais (embora serviços comercializáveis estejam claramente se tornando importantes também). Em outras palavras, países pobres tornam-se ricos ao produzir o que os países ricos produzem.

Por que a transição para atividades industrias modernas é um motor para o crescimento econômico? Conforme discuto em outro artigo $^{3}$ e seguindo uma longa tradição de modelos de economias duais, a resposta é que existem disparidades significativas entre as produtividades marginais sociais das partes tradicional e moderna das economias em desenvolvimento. Mesmo economias muito pobres têm atividades econômicas - horticultura na Etiópia, montadoras de automóveis na Índia, eletrônicos na China - nas quais os níveis de produtividade não estão muito distantes dos observados nas economias avançadas. Na medida em que os recursos deslocam-se das atividades tradicionais para essas atividades, a produtividade do conjunto da economia aumenta.

Tais disparidades se devem a uma ampla gama de características típicas do subdesenvolvimento. No artigo citado, discuto duas categorias gerais ${ }^{4}$. Uma tem a ver com fragilidades institucionais como proteção de direitos de propriedade e execução de contratos 
inadequados - , que se fazem sentir mais intensamente em atividades comercializáveis. A segunda está relacionada a várias falhas de mercado e externalidades - por exemplo, falhas no processo de spillover e de coordenação - associadas a atividades modernas. Em ambos os casos, o resultado é que a atividade industrial e o investimento são realizados em volume reduzido no equilíbrio de mercado. Qualquer coisa que acelere a transformação estrutural na direção dessas atividades deverá acelerar a taxa de crescimento econômico.

Embora as políticas concretas tenham variado significativamente entre os países bem-sucedidos, ainda é possível identificar alguns elementos comuns importantes. Em primeiro lugar, está claro que "fundamentos" sólidos cumpriram um papel, contanto que interpretemos o termo de maneira abrangente e não o associemos a nenhuma lista específica de políticas (como o Consenso de Washington ou as reformas de governança que estão na moda atualmente). Em segundo lugar, todos os países bem-sucedidos seguiram o que se pode chamar de políticas "produtivistas". Trata-se de políticas ativas voltadas a aumentar a lucratividade das atividades industriais modernas e a acelerar o deslocamento dos recursos em sua direção. Elas vão consideravelmente além da recomendação tradicional de reduzir a burocracia, a corrupção e o custo de fazer negócios. Implicam ainda (ou, às vezes, alternativamente): politicas industriais explícitas em apoio a atividades econômicas novas (proteção comercial, subsídios, incentivos tributários e creditícios, atenção governamental especial); câmbio subvalorizado para promover os bens comercializáveis; e um certo grau de repressão financeira para possibilitar crédito subsidiado, a criação de bancos de desenvolvimento e a subvalorização do câmbio.

É verdade que políticas industriais muitas vezes falham. Mas é também verdade que é virtualmente impossível encontrar países, seja na Ásia (Coreia do Sul, Taiwan), seja na América Latina (Chile), que prosperaram sem elas. Assim como no caso de políticas fiscais ou, digamos, de políticas educacionais, o que distingue os casos de sucesso dos casos malsucedidos nãoé a presença ou a ausência da política, mas a habilidade com a qual ela foi implementada.

O motivo pelo qual a subvalorização do câmbio funciona como um impulso poderoso para o crescimento econômico é que ela age como um tipo de política industrial. Ao elevar o preço relativo doméstico das atividades econômicas comercializáveis, ela aumenta a lucratividade de tais atividades e estimula a geração de capacidade e empregos nos setores industrias modernos que são centrais para o crescimento. Conforme discutido em detalhes no artigo citado acima, a associação entre taxas de câmbio subvalorizadas e crescimento acelerado é uma característica muito robusta dos dados do pós-guerra, particularmente para países de renda menor5.

[5] Ibidem. 
A subvalorização cambial tem a vantagem prática, comparada a políticas industriais explícitas, de ser uma política de amplo alcance que não requer seletividade e, assim, acarreta problemas menores de agência (rentismo [rent-seeking] e corrupção). Talvez isso explique o seu grande sucesso em estimular o desenvolvimento. Mas ela tem também muitas desvantagens. A mais importante, no presente contexto, é que funciona como um imposto doméstico sobre o consumo de bens comercializáveis (porque aumenta o preço relativo dos bens importados). É por isso que produz uma oferta excessiva de produtos comercializáveis - um superávit comercial. Esse último ponto tem uma relevância especial para o caso da China.

\section{A CHINA E A SUbValoRIZAÇÃo CAMBIAL}

A China nem sempre teve um grande desequilíbrio externo ou um câmbio subvalorizado. $\mathrm{Na}$ realidade, antes da década de 2000 , o país nunca teve um superávit de conta-corrente que excedesse 4\% (do PIB). Após ter quase alcançado esse nível em 1997, durante a crise financeira asiática, o seu superávit caiu constantemente até 2001 , quando então as coisas se alteraram. A partir de 2001, o superávit da China iniciou sua ascensão inexorável chegando a mais de $10 \%$ em 2007. Óndice de subvalorização que usei no artigo citado atinge, de forma semelhante, o ponto mais baixo em 2001 e cresce desde então ${ }^{6}$. É interessante que em 2001 a China tenha também ingressado na Organização Mundial do Comércio (OMC), após anos de negociação. Será uma coincidência que o desequilíbrio de conta-corrente da China começou a se ampliare sua subvalorização cambial passou a crescer no instante em que o país se tornou um membro da organização comercial?

Provavelmente não. O status de membro da OMC tornou difícil para a China, se não impossível, promover suas indústrias com o tipo de política industrial explícita com que o país vinha contando. Antes do fim dos anos 1990, as indústrias chinesas eram estimuladas por uma grande variedade de incentivos, incluindo elevadas barreiras tarifárias, incentivos ao investimento, subsídios à exportação e exigências de conteúdo nacional para as empresas estrangeiras. Como condição para se tornar membro da OMC, a China teve que interromper essas políticas. As tarifas de importação da China caíram de níveis que estavam entre os mais elevados do mundo até o início dos anos 1990 para níveis de apenas um dígito ao fim da década. Exigências de conteúdo local e subsídios à exportação foram eliminados; a subvalorização cambial, ou proteção através da taxa de câmbio, tornou-se o substituto de facto.

Se a subvalorização tem auxiliado o crescimento recente da China, que prejuízos ao crescimento decorreriam de a China deixar o seu 
câmbio ser apreciado (na ausência de mudanças compensatórias das políticas industriais)? No artigo citado, analiso regressões de dados que sugerem que a correlação parcial entre o meu índice de subvalorização (em log) e a taxa de crescimento anual é de o,026 para as nações em desenvolvimento 7 . (Por razões explicadas naquele trabalho, estou inclinado a considerar essa relação como causal.) No entanto, no caso $\mathrm{da}$ China essa estimativa sobe para 0,086 , um valor muito maior que pode ter como causa a grande reserva de mão de obra excedente e a grande disparidade entre os níveis de produtividade das partes moderna e tradicional da economia chinesa. Essa estimativa tem como consequência que uma apreciação de $10 \%$ reduziria o crescimento da China em 0,86 pontos percentuais.

Segundo muitas avaliações, incluindo minhas estimativas (baseadas em comparações de níveis de preço com ajuste para efeitos Balassa-Samuelson), o câmbio da China está subvalorizado cerca de $25 \%$. Corrigiressa subvalorização resultaria em uma redução de 2,15 pontos percentuais por ano do crescimento chinês $\left(=0,25^{\prime} 0,086\right)$. Esse é um efeito considerável, mesmo para o padrão elevado do histórico de crescimento chinês. E, o que é mais importante, uma desaceleração dessa magnitude colocaria a China abaixo do limiar dos $8 \%$ de crescimento que os seus líderes parecem acreditar ser necessários para manter a paz social e evitar conflitos.

Ninguém sabe de onde vem, na realidade, o valor de $8 \%$. Ele claramente não tem uma base científica. Muitos especialistas em China pensam que a sociedade e a comunidade política chinesas são capazes de lidar com um crescimento muito menor do que esse. No entanto, mesmo que as implicações políticas pudessem ser deixadas de lado, não seria um resultado desejável o mais poderoso motor de redução de pobreza que o mundo jamais conheceu experimentar uma desaceleração significativa. Éverdade que outros países que contaram com as exportações para crescer rapidamente - como Alemanha,Japão e Coreia do Sul - tiveram, no fim, que deixar as suas taxas de câmbio serem apreciadas. Mas a China ainda é um país muito pobre, com pouco mais de um décimo do nível de renda dos Estados Unidos. O país tem uma imensa reserva de mão de obra excedente no campo.E, além disso, tem que conviver com restrições a suas políticas industriais que nenhum desses outros países, em tempos pré-OMC, tiveram que respeitar.

\section{SUPERÁVIT COMERCIAL, EXPORTAÇÕES OU PRODUÇÃO DE BENS COMERCIALIZÁVEIS?}

A taxa de câmbio real afeta a balança comercial, a oferta de exportações e a produção de bens comercializáveis. Qual desses é o canal pelo qual uma subvalorização estimula o crescimento?
[7] Ibidem.

\footnotetext{
[8] Os efeitos Balassa-Samuelson consistem em diferenças de níveis de preço entre países com níveis diferentes de desenvolvimento, decorrentes do ritmo distinto de variações da produtividade de setores de bens comercializáveis em relação a setores de bens não comercializáveis. Tais efeitos podem ser derivados de um modelo desenvolvido independentemente por Béla Balassa e Paul Samuelson. [N. T.]
} 
[9] Rodrik. "Growth after the Crisis", op. cit.
Considere a diferença entre as hipóteses "exportações" e "bens comercializáveis". Para as quantidades exportadas importarem para o crescimento no longo prazo, deve-se acreditar que ocorram spillovers de algum tipo (que têm sido difíceis de documentar) como consequência das exportações, ou deve-se acreditar na explicação que esbocei acima, segundo a qual os bens comercializáveis são especiais porqueé aí que se concentram as atividades com maior produtividade. As duas explicações diferem na importância que atribuem ao ato de exportar em si. A hipótese "spillover consequente de exportações" depende da existência de externalidades tecnológicas ou de comercialização criadas quando um bem comercializável cruza uma fronteira internacional. Para a hipótese "comercializáveis são especiais", é indiferente se o comércio internacional ocorre ou não.

Em um artigo de 2009, realizei uma série de comparações entre esses mecanismos distintos 9 . Estimei regressões de crescimento com efeitos fixos para países e períodos de tempo, usando um painel de subperíodos quinquenais. Os regressores, além dos efeitos fixos, foram a renda defasada (para dar conta da convergência), a parcela de valor adicionado industrial no PIB, a parcela das exportações no PIB e o superávit comercial como percentual do PIB.

Quando as parcelas da indústria e das exportações são incluídas ao mesmo tempo, ambas são estatisticamente significativas, mas o impacto estimado da atividade industrial é duas vezes mais forte. Um aumento da parcela industrial de um desvio-padrão deve, segundo a estimativa, elevar o crescimento em 1,6 ponto percentual, enquanto o aumento correspondente da parcela das exportações eleva o crescimento em apenas 0,7 ponto percentual. Além disso, verifica-se que o resultado para a parcela das exportações não é robusto. Quando a amostra é limitada aos dados posteriores a 1990 ou quando algumas observações correspondendo a países com parcelas de exportações muito elevadas (por exemplo, Luxemburgo e Hong Kong) são excluídas, os coeficientes estimados para as exportações tornam-se insignificantes. Talvez de forma mais essencial, quando restringimos a amostra para os países em desenvolvimento, o coeficiente para a parcela das exportações torna-se levemente negativo (e estatisticamente insignificante), enquanto o coeficiente da parcela industrial aumenta e mantém-se fortemente significativo. A competição entre a atividade industrial e a orientação para as exportações tem um claro vencedor.

Já a competição entre a parcela industrial e o superávit comercial também tem um claro vencedor. Quando se controla para a parcela industrial no PIB, os superávits comerciais não exercem nenhum efeito positivo adicional sobre o crescimento econômico. Isso é verdade para a amostra completa, para os dados posteriores a 1990, para amostras em que déficits ou superávits comerciais grandes foram removidos 
e para amostras restritas a países em desenvolvimento. Em cada um desses casos, a variável industrial é altamente significativa, mas o superávit comercial não.

A implicação para a China e para as nações em desenvolvimento que se prenderam a superávits comerciais ou exportações como seus "motores do crescimento" é clara: o que realmente importa é a produção de bens comercializáveis (da qual a produção industrial serve como proxy). Nem as exportações nem os superávits comerciais são cruciais, desde que a demanda doméstica porbens comercializáveis possa ser ampliada paralelamente à oferta doméstica.

\section{MUDANÇA ESTRUTURAL E CRESCIMENTO SEM SUPERÁVITS COMERCIAIS}

Retornemos à interpretação subjacente à dinâmica de crescimento que esbocei acima. Nessa perspectiva, países pobres são pobres porque muito pouco dos seus recursos está em atividades modernas, de alta produtividade. Períodos de crescimento rápido ocorrem quando há uma rápida transformação estrutural de setores tradicionais de baixa produtividade para atividades modernas de alta produtividade. A razão pela qual essa transformação não é um processo automático, impulsionado pelo mercado, é que existem graves falhas de mercado e institucionais cujos custos são sustentados desproporcionalmente pelos setores modernos. Algumas vezes a transformação é bloqueada em decorrência de baixa poupança doméstica e alto custo de capital, que retardam o investimento e a mudança estrutural. Mas, mais tipicamente, o problema está em uma grande diferença entre retornos privados e sociais em setores modernos. Esses setores estão sujeitos tanto a spillovers de aprendizado como a falhas de coordenação e a altos custos impostos por fragilidades em instituições legais e regulatórias. É difícil eliminar tais fragilidades no curto prazo, e a experiência das economias avançadas indica que elas podem ser enfrentadas apenas ao longo de décadas, se não séculos.

Ainda que fosse desejável abordar diretamente essas limitações, por meio da remoção das falhas de mercado e da reforma das instituições, na prática tal agenda é muito ampla e ambiciosa e, por isso, irrealista. Como dito anteriormente, países bem-sucedidos seguiram estratégias de crescimento que aliviaram essas restrições de modo indireto, por meio da elevação, por outros meios, da lucratividade relativa das atividades modernas. O que todas essas estratégias têm em comum é que elas agem como subsídios aos bens comercializáveis.

Quando reduzimos tais estratégias a sua essência, torna-se mais fácil compreender o queé central e o queé incidental para seu funcionamento. Em particular, podemos ver que a estratégia de subsidiar bens comercializáveis não precisa estar associada a taxas de câmbio 
subvalorizadas e a superávits comerciais. É possível elevar os incentivos à produção de bens comercializáveis, e o fazer tanto quanto for necessário, sem criar consequências indesejadas para o restante do mundo na forma de desequilíbrios comerciais. Diferentemente da subvalorização cambial, que taxa o consumo doméstico de bens comercializáveis, uma política de subsidiar bens comercializáveis de forma explícita (combinada com políticas macroeconômicas que mantêm o equilíbrio externo) estimula o consumo doméstico de bens comercializáveis.

Que forma esse subsídio deve assumir na prática? Conforme discutido no meu artigo de 2009 , existem três abordagens gerais: i) políticas industriais; ii) redução dos custos dos insumos dos bens comercializáveis; e iii) políticas de renda ${ }^{10}$. Todas elas colocam desafios práticos de implementação, de forma que a combinação adequada depende das circunstâncias de cada país.

Em princípio, a política industrial éideal para o problema em questão. O que se deve fazer é elevar a lucratividade relativa dos produtos não tradicionais queenfrentam grandes externalidades de informação ou falhas de coordenação, ou que padecem de forma particularmente intensa do ambiente institucional pobre. É isso que uma boa política industrial busca realizar. Isenções fiscais, crédito direcionado, subsídios à folha de pagamentos, subsídios ao investimento, zonas de processamento de exportações são algumas formas pelas quais políticas industriais podem ser implementadas. O que é característico dessas políticas é que elas visam empresas ou setores específicos e, assim, privilegiam alguns em detrimentos de outros. É claro que é isso que a torna polêmica. Mas, se o direcionamento for feito de forma amplamente satisfatória - se focar em atividades novas nas margens exteriores das competências básicas de um país - , o ganho potencial será grande. A vantagem da política industrial em relação à subvalorização cambial é precisamente que ela permite maior ajuste fino e discriminação: bens comercializáveis tradicionais (como produtos primários e produtos industriais em cuja produção o país já se consolidou) não precisam ser subsidiados e o consumo de bens comercializáveis não precisa ser taxado.

Existe ainda um sentido no qual subsídios para bens comercializáveis modernos podem vazar para além das fronteiras. Mesmo que a oferta líquida de bens comercializáveis não cresça no agregado, a oferta líquida daqueles que foram escolhidos para serem estimulados crescerá. Outros países estarão na ponta receptora disso e, se eles ficarem passivos, os seus próprios incentivos industriais serão enfraquecidos. Mas a forma correta de especificar esse problema é dizer que o uso de políticas industriais "ótimas" em alguns países eleva o custo de não usar tais políticas nos outros. $\mathrm{Na}$ medida em que alguns países ali- 
viam suas imperfeições de mercado, os custos de não lidar com tais imperfeições torna-se exacerbado em outros lugares. Assim, quando todos os países estiverem seguindo políticas industriais que são ótimas na sua perspectiva, não haverá efeitos indesejadas a combater. Os efeitos em questão podem ser efetivamente neutralizados, desde que os outros países (em desenvolvimento) também sigam políticas industriais apropriadas.

O principal obstáculo material à utilização mais ampla de políticas industriais pelos maiores países em desenvolvimento é o Acordo sobre Subsídios da OMC. Esse acordo proíbe o uso de subsídios na forma de gastos fiscais condicionados ao desempenho exportador. De maneira mais grave, ele também torna "contestável" o uso de subsídios que tenham o efeito de aumentar as exportações, mesmo que não sejam diretamente condicionados pelas exportações. (Os países menos desenvolvidos são isentos dessas regras.) Uma aplicaçãoliteral dessa regra impediria muitos tipos de política industrial cujo objetivo é precisamente elevar a oferta doméstica de bens comercializáveis.

Em um mundo em que o crescimento econômico requer o fomento de atividades econômicas modernas em nações em desenvolvimento, oAcordo sobre Subsídios tem pouco sentido, do ponto de vista econômico. Ele impossibilita uma política desejável, queé a segunda melhor alternativa para promover diversificação econômica e mudança estrutural, e tem a consequência indesejada de induzir governos a adotar uma política inferior (levando em conta os seus efeitos em termos de desequilíbrios comerciais), qual seja, taxas de câmbio subvalorizadas. O que é ainda pior, o acordo pode estimular o protecionismo comercial como medida defensiva contra importações industriais. Se quisermos maior supervisão internacional sobre práticas cambiais, como acho que devemos querer, precisaremos relaxar substancialmente o controle sobre subsídios industriais.

DANI RODRIK é professor de Economia Política Internacional “Rafiq Hariri” da Escola de Governo Kennedy, Harvard (EUA).
Recebido para publicação em 20 de outubro de 2010 .

NOVOS ESTUDOS

CEBRAP

89, março 2011

pp. 59-68 